\title{
Generalized cliticization and agreement asymmetries in Asturian possessive DPs
}

\author{
Guillermo Lorenzo \\ Universidad de Oviedo \\ glorenzo@uniovi.es
}

Received: $15-12-2019$

Accepted: 08-06-2020

\begin{abstract}
This paper explores the generalization of the Affix Support condition to clitics, in order to explain the most distinctive properties of the different kinds of possessive DPs in Asturian. In doing so, the paper also unveils some derivational mechanisms with the potential of explaining the different kinds of agreement asymmetries typical of possessive DPs in this Romance language. From a broader theoretical perspective, the paper aims to support an architectural model of the Faculty of Language in which the boundary between Core Syntax and Phonology is more porous than customarily assumed, insofar as the former incorporates conditions of a kind traditionally referred to the Externalization component.
\end{abstract}

Keywords: Asturian; possessives; clitics; agreement; sound-syntax interface.

\section{Table of Contents}

1. Introduction

2. Possessive DPs in Asturian: A descriptive approximation

3. Possessive DPs in Asturian: An explanatory approach
4. Agreement asymmetries in Asturian possessive DPs 5. Concluding remarks References 


\section{Introduction ${ }^{1}$}

This paper is an attempt to extend the Generalized Cliticization model suggested by Richards (2016: 57) to explain the different surface forms of possessive Determiner Phrases (DPs) in Asturian. According to Richards' thesis, affixes of all kinds are required to fulfill a phonological condition which applies at Syntax. Richards' own formulation of this constraint is the following:

\section{(1) Affix Support}

If a head is an affix, there must be a metrical boundary in the direction in which it attaches. (Richards 2016: 27)

According to Richards (2016: 57), in as much as the model appears to be projectable to units other than affixes, a generalized version of (1) might more broadly refer to clitics. In this paper, such an extended interpretation of (1) is applied to possessive (clitic) pronouns, which in Asturian needs a kind of support which parallels the one explored at length by Richards in the case of affixes.

The fact that (1) is an 'early' phonological filter, as it applies at Syntax, is somewhat unconventional, as it runs against the strong encapsulation model which is more or less consensual within the generativist framework. According to this model, different levels of analysis (e.g. Syntax and Phonology) correspond to autonomous modules and their domain-specific processes operate on a strictly sequential basis (namely, Phonology after Syntax). Thus, Richards advocates a kind of interpenetration of phonological criteria within the syntactic module, which presents itself as a partial correction of the run-of-the-mill division of labor of current generative grammar (see Chomsky 1995; Hornstein et al. 2005, for a general characterization of the minimalist frame). This paper aims to offer a particular contribution to the Generalized Cliticization model, testing its explanatory capacity to deal, in a principled way, with the different surface forms which nominal possessive constructions may attain in Asturian. In doing so, the model will also be confronted with the challenge of explaining the variety of agreement asymmetries which are attested in these constructions in Asturian.

The paper is organized as follows. Section 2 offers a descriptive approximation to the different possessive nominal constructions allowed by the syntax of the main varieties of Asturian (Western, Central, and Eastern). ${ }^{2}$ In section 3, a principled explanation is suggested for said constructions, based on the centrality of the generalized version of the condition (1) above. Section 4 is

1 This paper has benefitted from a grant of the Spanish Government (DALiV: Development, acquisition and mechanisms of linguistic variation; FFI201787699-P). I am grateful for the insightful suggestions of three anonymous Isogloss reviewers. The paper is dedicated to the memory of Carme Picallo. As every single student of the syntax of possession in Romance, I am in debt to her contributions to this field.

2 As regards the main concerns of this paper, I shall not descend to a level of dialectological definition below the one adopted by ALLA (2001). Details from a relatively more 'microscopic' perspective will be introduced as footnotes, along with relevant bibliographic sources. 
devoted to specifying how this account predicts different asymmetric agreementpatterns observed in Asturian, with a special focus on the 'mass/count' distinction which the agreement system must also obey. Section 5 present some concluding remarks.

\section{Possessive DPs in Asturian: A descriptive approximation}

The grammar of the Academy of the Asturian Language (henceforth, ALLA) lists four main types of nominal possessive constructions in Asturian (ALLA 2001: 107-114). Their most distinguishing traits are synthesized as follows. ${ }^{3}$

I. Prenominal possessive construction. This type comprises a possessive (Poss) preceding a noun $(\mathrm{N})$, and an article (Art) anteceding Poss and N. Poss appears in a form invariable for gender $(\gamma)$, except for the 1st and 2nd person forms for more than one possessor - see (5) below, albeit it agrees in number (\#) with both Art and N; Art agrees in number and gender with N. ${ }^{4}$ (2) provides the basic skeleton of the construction, and (3)-(6) offer some examples: ${ }^{5}$

(2) Type I

$\operatorname{Art}_{\{\#, \gamma\}}+\operatorname{Poss}_{\{\#\}}+\mathrm{N}_{\{\#, \gamma\}}$

$$
\begin{aligned}
& \text { a. el mio neñu } \\
& \text { the-MS.SG my-SG boy-MS.SG } \\
& \text { 'my boy' } \\
& \text { b. la mio neña } \\
& \text { the-FM.SG my-SG girl-FM.SG } \\
& \text { 'my girl' }
\end{aligned}
$$
a. $\operatorname{los}$
tos neños
the-MS.PL your-PL boy-MS.PL 'your boys'
b. les tos neñes
the-FM.PL your-PL girl-FM.PL 'your girls'

\footnotetext{
3 I do not deal here with some specific possessive configurations which follow a particular logic within the Asturian system, namely, the general lack of the definite article in possessive phrases denoting kinship relations or when embedded as vocatives in exclamative contexts. See ALLA (2001: 112).

4 In the Western variety of Asturian (see Figure 1 in the main text), it is attested a prenominal possessive construction in which the possessive also displays gender agreement. In fact, Rodríguez Castellano (1957: 172-177) points to this fully inflected variant as the most common one in this area. In some Central and Eastern sub-varieties, the possessive is also invariable for number (Rodríguez Castellano 1957: 180). For descriptions of all these sub-variants, see also Neira (1976: 108), and Zamora Vicente (1985: 173), and Lorenzo (1998), for a formal account.

5 Except when indicated, the examples of this paper are taken from ALLA (2001).
} 
(5)
a. el nuesu llibru the-MS.SG our-MS.SG book-MS.SG 'our book' the-FM.SG our-FM.SG house-FM.SG 'our house'
b. la nuesa casa

(6)
a. los sos llibros
the-MS.PL her/his.PL book-MS.PL
'her/his/their books'
b. les sos cases
the-FM.PL her/his.PL house-FM.PL
'her/his/their houses'

II. Postnominal possessive construction (A). ${ }^{6}$ In this type, Poss and N invert positions relative to Type I, and all the rest remains equal:

(7) Type II

$\operatorname{Art}_{\{\#, \gamma\}}+\mathrm{N}_{\{\#, \gamma\}}+\operatorname{Poss}_{\{\#\}}$
a. el neñu mio the-MS.SG boy-MS.SG my-SG 'my boy'
b. la neña mio the-FM.SG girl-FM.SG my-SG 'my girl'

(9)
a. $\operatorname{los}$
neños
tos
the-MS.PL boy-MS.PL your-PL 'your boys'
b. les neñes tos
the-FM.PL girl-FM.PL your-PL 'your girls'
a. el
llibru
nuesu
the-MS.SG book-MS.SG our-MS.SG
'our book'
b. la casa nuesa
the-FM.SG house-FM.SG our-FM.SG
'our house'

\footnotetext{
6 The A/B distinction between the two non-periphrastic constructions with postnominal possessive is the one used by ALLA (2001). In this paper, I refer to them as Type II and Type III, respectively, in order to obtain an easier system for referring to them.
} 
(11)
a. los llibros sos
the-MS.PL book-MS.PL her/his.PL 'her/his/their books'
b. les cases sos
the-FM.PL house-FM.PL her/his.PL
'her/his/their houses'

III. Postnominal possessive construction (B). This type exhibits the same relative order of constituents as II, but now Poss exhibits gender variation as well. Thus, all the three components agree in number and gender:

(12) Type III

$\operatorname{Art}_{\{\#, \gamma\}}+\mathrm{N}_{\{\#, \gamma\}}+\operatorname{Poss}_{\{\#, \gamma\}}$

a. el neñu míu the-MS.SG boy-MS.SG my-MS.SG

'my boy'

b. la neña mía the-FM.SG girl-FM.SG my-FM.SG 'my girl'
a. $\operatorname{los}$
neños
tuyos

the-MS.PL boy-MS.PL your-MS.PL 'your boys'

b. les neñes tuyes the-FM.PL girl-FM.PL your-MS.PL 'your girls'
a. el
llibru
nuesu
the-MS.SG book-MS.SG our-MS.SG
'our book'
b. la
casa nuesa
the-FM.SG house-FM.SG our-FM.SG
'our house'
a. $\operatorname{los}$
llibros
suyos
the-MS.PL book-MS.PL her/his.MS.PL
'her/his/their books'
b. les cases suyes
the-FM.PL house-FM.PL her/his.MS.PL
'her/his/their houses'

IV. Periphrastic possessive construction. In the periphrastic possessive construction, a postnominal Poss, invariable for number and gender, is preceded by the preposition $d e$ 'of':

$$
\begin{aligned}
& \text { (17) Type IV } \\
& \operatorname{Art}_{\{\#, \gamma\}}+\mathrm{N}_{\{\#, \gamma\}}+\mathrm{de}+\text { Poss }
\end{aligned}
$$



a. el neñu de mio the-MS.SG boy-MS.SG of mine 'my boy'
b. la neña de mio the-FM.SG girl-FM.SG of mine 'my girl'
a. $\operatorname{los}$
neños
de to
the-MS.PL boy-MS.PL of yours 'your boys'
b. les neñes de to the-FM.PL girl-FM.PL of yours 'your girls'
a. el
llibru de nueso the-MS.SG book-MS.SG of ours 'our book'
b. la casa de nueso the-FM.SG house-FM.SG of ours 'our house'
a. los
llibros
de so
the-MS.PL book-MS.PL of hers/him 'her/his/their books'
b. les cases de so the-FM.PL house-FM.PL of hers/him 'her/his/their houses'

According to ALLA (2001: 108), among the different postnominal possessive constructions (Types II, III, and IV), Type II is the most common one and the one preferable from a normative perspective; Type IV is attested in the Western and Central varieties of Asturian, but absent in the Eastern dialect (see Figure 1).

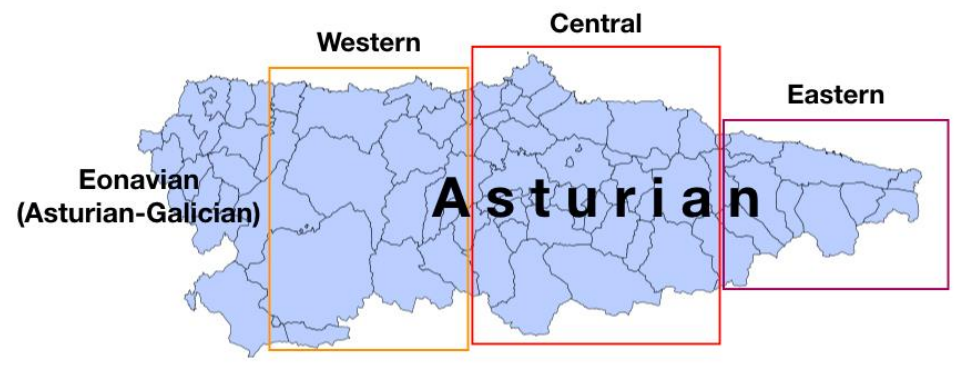

Figure 1. Main dialectological domains of Asturian 


\section{Possessive DPs in Asturian: An explanatory approach}

In this section, I try to offer a unified explanatory account of the different possessive constructions reviewed in section 2 , which is ultimately based on Kayne's (1994) approach to some postnominal possessive constructions of English (e.g. the (two) pictures of John's) (see Szabolsci 1981, 1983, for some antecedents; Bernstein 2006 and Bernstein \& Tortora 2005, for some subsequent developments of the same approach). Here, I claim that the bottom of Kayne's underlying structure for such constructions is shared by all the Asturian possessive structures described above. For concreteness, I assume that such a structural ground corresponds to a kind of predicative relation between the possessive and the nominal component of the different constructions, which is held through an abstract agreement head of a nominal type (Agr/D). In line with Richards (2016), I also claim that possessives belong to the kind of items $(k)$ which must fulfill Affix Support (1) in syntax ( $k$ will systematically appear in the figures signaling the direction in which the items concerned attach). Figure 2 tries to capture this suggested inner structural layer, which I claim to be shared, except some minor details to be specified, by all possessive constructions. Henceforth, Figure 2 is referred to as the 'possessive base.'

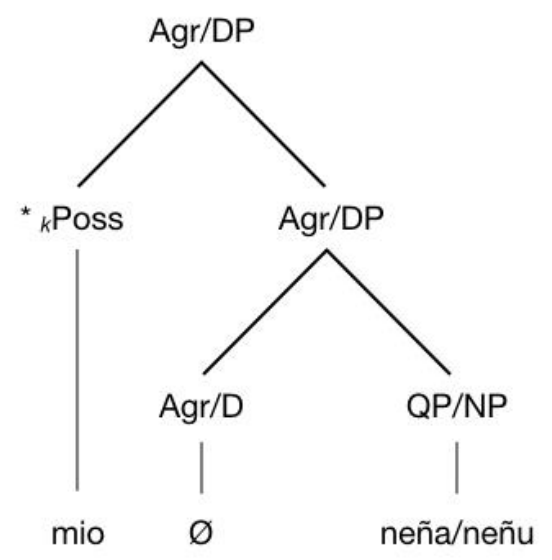

Figure 2. The possessive base

Before proceeding with more structural and derivational claims, some important qualifications are to be made as regards the Asturian possessives. Contrarily to what happens, for example, in Spanish (Bernstein 2006), an opposition like the one between 'deficient' (prenominal) and 'strong' (postnominal) possessive forms, along the lines of Cardenaletti (1998), does not apply in the case of Asturian. In this language, the prenominal forms are not systematically "less complex" variants of the postnominal ones (Bernstein 2006: 64), and, critically, gender is not "robustly expressed" in the latter (Bernstein 2006: 67). These observations justify that a more compact and unified system of analysis is desirable in the case of Asturian. Moreover, the fact that the Asturian forms are in general deficient ones particularly encourages the projection of Richards' 'support' mechanism in the present cases. In this respect, it is also important to observe that the Asturian possessives, irrespective of their specific placement, are consensually introduced in the literature as the site of stress, 
regardless of their lack of autonomy as clitics. In the formulation of Richards' (2016) hypothesis, this entails that when they attach some item to their left-hand side, a metric boundary is introduced in that side.

Now, going back to Figure 2, the asterisk that accompanies ${ }_{k}$ Poss in Figure 2 signals that this structure will crash at PF unless it receives support by another element introducing such metrical boundary to its left-hand side. The nearest unit to ${ }_{k}$ Poss (Agr/D) then undergoes I-Merge, extending the domain of Agr/DP. However, this move is not enough, as Agr/D is a phonologically null unit, incapable of offering Affix Support as prescribed by (1). Such a failure then triggers the introduction, via E-Merge, of a dummy determiner $\left(\mathrm{d}_{k}\right)$, which must agree with Agr/D. This item is marked as a clitic itself, but with the specification that Affix Support must be fulfilled by a metrical boundary to its right-hand side. Thus, at PF, where Agr/D is transparent, $\mathrm{d}_{k}$ and ${ }_{k}$ Poss support each other and the resulting structure converges. Note that the root of the resulting structure is labeled as DP. I claim that this case matches those wherein labeling is based on the following Chomskyan heuristics: "LA [Labelling Algorithm] finds the same most prominent element $[\mathrm{D}$, in this case] in both terms, and can take that to be the label of $\alpha "$ (Chomsky 2013: 45). The resulting structure corresponds to the prenominal possessive construction (Type I), exemplified in (3)-(6) above. Figure 3 tries to capture its derivation as explained above.

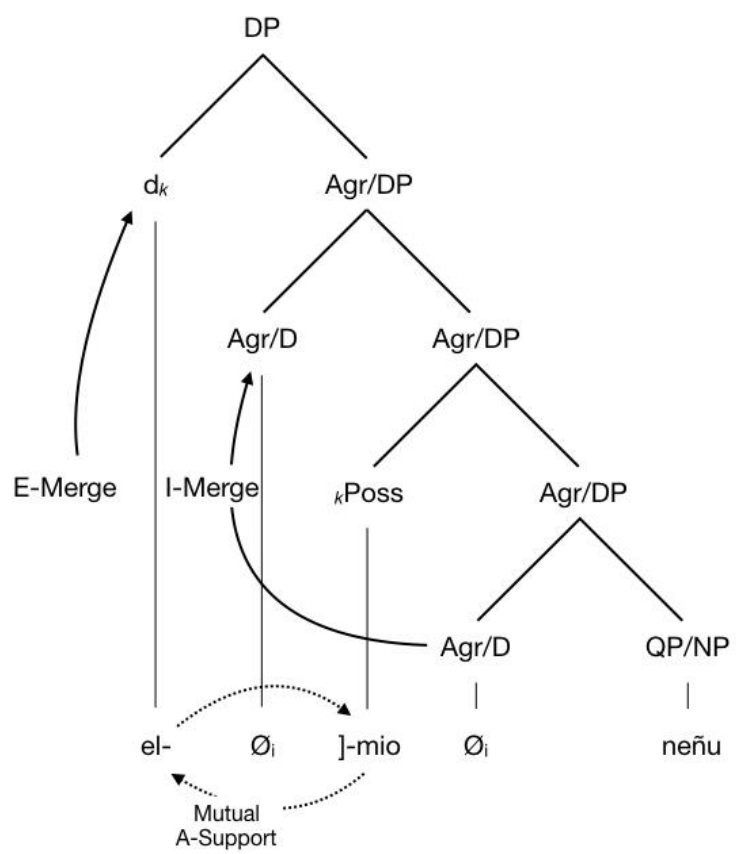

Figure 3. Prenominal possessive construction (Type I: e.g. el mio neñu)

In this figure, an explanation is still lacking for the fact that the possessive skips gender agreement in all persons (el mio neñu, la mio neña), except the 1st and 2nd ones for many possessors (el nuesu llibru, la nuesa casa). My tentative answer to this aspect of the construction is twofold. Firstly, once Agr/D moves, an Agr/D-chain is set that needs to be satisfied just once (Brody 1997) in terms of $\varphi$ feature agreement proper (i.e. number + gender), which I take to be a filter condition to be satisfied at PF. As a consequence, it suffices that $\mathrm{d}_{k}$ and QP/NP $(e l$ 


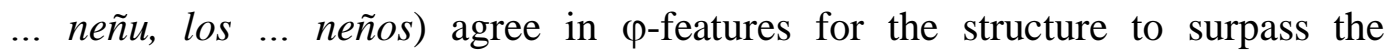
corresponding PF condition. Notwithstanding this, number, which contrarily to gender, is an interpretable feature, remains active at LF, so number agreement is to be respected all along the Agr/D-chain (los tos neños, les tos neñes). Poss, consequently, has to incorporate number morphology and to agree with $\mathrm{d}_{k}$ and $\mathrm{QP} / \mathrm{NP}$ in terms of this specific feature alone. Note that, as a consequence, I am taking the following two interface conditions from Adger \& Ramchad (2005) to be putative specializations of the semantic (22a) and the phonological (22b) interfaces, respectively:

\section{a. Full Interpretation}

Every feature must be mappable to an interpretation at the interface.

b. Interpret Once under Agree

Features in an Agree chain are interpreted once.

(Adapted from Adger \& Ramchad 2005: 174)

This explanation works for all feature combinations, except the 1st and 2nd person for more than one possessor. In this case, Poss must display the whole set of interpretable and classificatory agreement features (i.e. number + gender; $\mathrm{el}$ nuesu llibru, la nuesa casa). My suggestion, also tentative, is that these specific possessives are subject to an exceptional kind of morphological composition within the Asturian possessive paradigm, in that the number feature cannot be realized independently of one or another gender value. Thus, I suggest that the following contrast is operative in the Asturian morphology:

(a) On the one hand, all forms, except the 1st and 2nd person for many possessors, have a 'neutral' independent form: mio, to, so. ${ }^{7}$ Moreover, the number affix is independent from the gender one, so the neutral form exhibits number variation alone, if not forced to do otherwise. Gender is, according to my interpretation, an optional specification of number. Consequently, the model allows for a neutral plural form, uninflected for gender: mios, tos, sos.

Regarding this point, an anonymous reviewer makes the important observation that the suggested kind of dependence of gender on number appears to be cross-linguistically uncommon and challenged by phenomena like the ' $l e$ for-les' one in the Spanish system of pronominal clitics (DeMello 1992, Ausín \& Fernández Rubiera 2017). In Spanish, the non-plural dative le may be coindexed with a plural IO (e.g. no le digas eso a los niños; NEG DAT.SG this to.DAT the.PL child.PL; 'do not say that to the children'). No parallel 'la-for-las' or 'lofor-los' phenomenon exist with accusative pronouns. The difference between the accusative and the dative paradigm is the presence/absence of gender morphology respectively. Consequently, it appears to be (the lack of) gender which determines the availability of neutralizing number, thus suggesting the dependence of number on gender. Nevertheless, some other phenomena point to the availability of opposite kind of dependence of gender on number in Romance languages. In Romanian, for example, there exists a large class of nouns (customarily referred to as 'neuter nouns'), which are masculine in the singular and feminine in the 
plural (Farkas 1990, Ritter 1993). Thus, one has, on the one hand, un scaun confortabil (a.MS.SG chair comfortable.MS.SG; 'a comfortable chair') and, on the other hand, niste scaune confortabile (some chairs comfortable.FM.PL; 'some comfortable chairs'). In cases like these, it appears to be clear that it is gender which depends on number. Thus, from a Romance perspective, my claim concerning Asturian is not a complete exception.

(b) On the other hand, the forms of 1st and 2nd person for more than one possessor are morphologically different, in that the neutral form is a nonindependent stem (nues-, vues-), and number and gender cannot appear independently of each other.

Figure 4 tries to capture the contrast between (a) and (b) at a subatomic level of morphological analysis. The left-hand side of the figure emphasizes the potential independence of ${ }_{k}$ Poss, as well as the autonomy of number from gender, interpreting the latter as a non-obligatory specification of the former; the righthand side of the figure expresses the complementary properties of the alternative model, emphasizing the affixal nature of Poss (Poss-), together with the lack of autonomy of gender from number.

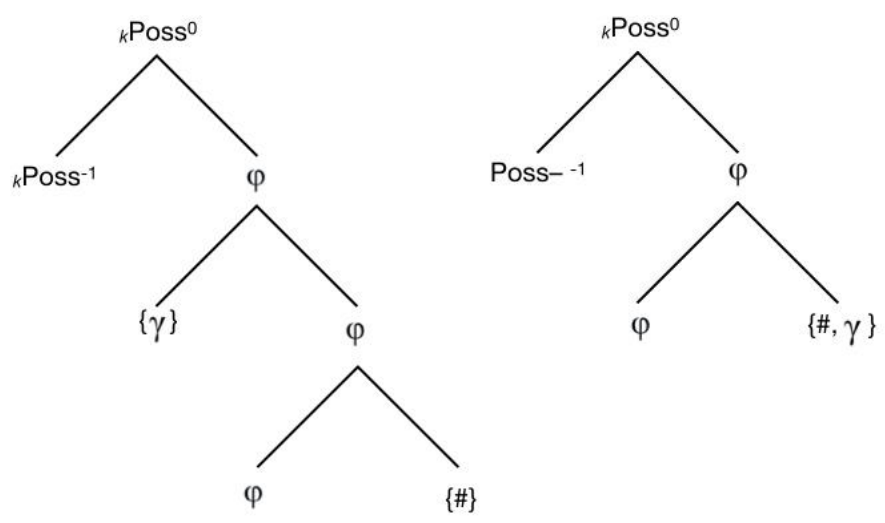

Figure 4. Alternative sub-atomic composition of the Asturian possessives

Table 1 offers a complete paradigmatic view of Asturian possessives, organized according to the interpretation above: ${ }^{8}$

8 See Rodríguez Castellano (1957) for an exhaustive account of the phonetic variants of every single unit of this paradigm. 
Table 2. Inflectional paradigm of the Asturian possessives. Pale gray: with free neutral; dark gray: without free neutral.

\begin{tabular}{|c|c|c|c|c|c|c|c|}
\hline \multirow{3}{*}{$\begin{array}{c}\text { one } \\
\text { possessor }\end{array}$} & \multirow{3}{*}{$\frac{1 \mathrm{st}}{2 \mathrm{nd}}$} & \multirow{3}{*}{$\begin{array}{l}\text { mio } \\
\text { to }\end{array}$} & \multirow{3}{*}{$\operatorname{mio}(\mathrm{s})$} & \multirow{3}{*}{ mí(a) } & \multirow{3}{*}{ mí(es) } & \multirow{3}{*}{$\begin{array}{l}\text { mí(u) } \\
\text { tuy(u) }\end{array}$} & \multirow{3}{*}{$\begin{array}{l}\text { mí(os) } \\
\text { tuy(os) }\end{array}$} \\
\hline & & & & & & & \\
\hline & & & & & & & \\
\hline \multirow{7}{*}{$\begin{array}{l}\text { more than } \\
\text { one } \\
\text { possessor }\end{array}$} & $3 \mathrm{rd}$ & so & $\mathrm{so}(\mathrm{s})$ & suy(a) & suy(es) & $\operatorname{suy}(u)$ & suy(os) \\
\hline & & $\mathrm{sg}$ & $\mathrm{pl}$ & $\mathrm{sg}$ & $\mathrm{pl}$ & $\mathrm{sg}$ & $\mathrm{pl}$ \\
\hline & & \multicolumn{2}{|c|}{ neutral } & \multicolumn{2}{|c|}{ feminine } & \multicolumn{2}{|c|}{ masculine } \\
\hline & & $\mathrm{sg}$ & $\mathrm{pl}$ & $\mathrm{sg}$ & $\mathrm{pl}$ & $\mathrm{sg}$ & $\mathrm{pl}$ \\
\hline & $3 \mathrm{rd}$ & so & $\mathrm{so}(\mathrm{s})$ & $\operatorname{suy}(a)$ & suy(es) & $\operatorname{suy}(u)$ & suy(os) \\
\hline & 2nd & \multicolumn{2}{|c|}{ vues- } & vues(a) & vues(es) & vues(u) & vues(os) \\
\hline & $1 \mathrm{st}$ & \multicolumn{2}{|c|}{ nues- } & nues(a) & nues(es) & nues(u) & nues(os) \\
\hline
\end{tabular}

From a possessive base similar to the one depicted above (Figure 2), the Asturian grammar may also resort to three alternative convergent strategies for constructing possessive nominals. The first that I am going to review is very close to the prenominal possessive construction (Figure 3), in that Agr/D also raises and an agreement chain is formed. However, this alternative structure is different in that Agr/D may select a QP (tres neños), which is also possible in the case of type I, or a full-fledged DP (el neñu). My interpretation is that an Agr/D atom with a slightly different feature composition is chosen in each case, namely, one which selects QP/NP for first Merge (Type I), or one which selects DP/QP for the same purpose (Type III). Let me refer to this latter atom as $\mathrm{Agr} / \mathrm{D}^{+}$. The selection properties of $\mathrm{Agr} / \mathrm{D}^{+}$entails that when an article opens the structure, it has been pied-piped with a whole DP from the internal argument position of the possessive base. This is relevant for reasons which will became clear below.

The intermediate structure resulting from $\mathrm{Agr} / \mathrm{D}^{+}$raising is depicted in Figure 5.

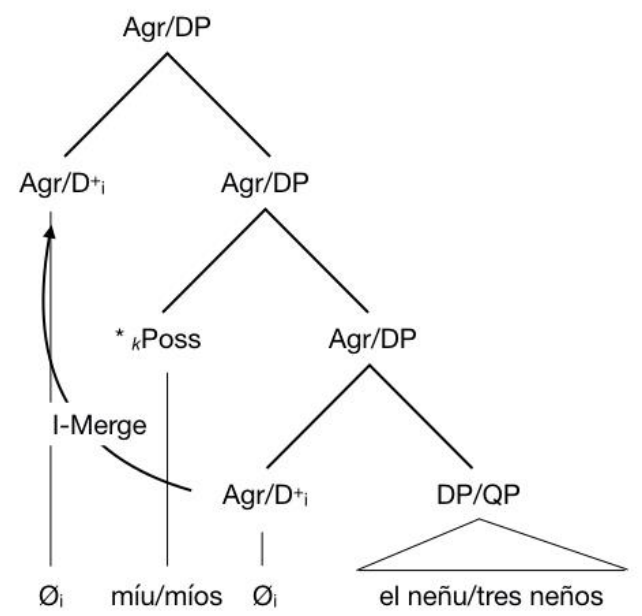

Figure 5. Postnominal possessive construction (Type III: e.g. el neñu míu). Intermediate structure 
This is, again, an illegitimate structure, as ${ }_{k}$ Poss still requires an item to its left in order to satisfy Affix Support. From the structure in Figure 5, this can be done by raising the internal nominal structure (DP/QP) to Spec, Agr/DP, from which the PF-legitimate structure in Figure 6 ensues. My analysis is thus similar to Bernstein's (2006: 65) 'XP-raising analysis' for deriving the placement of postnominal possessives in Spanish.

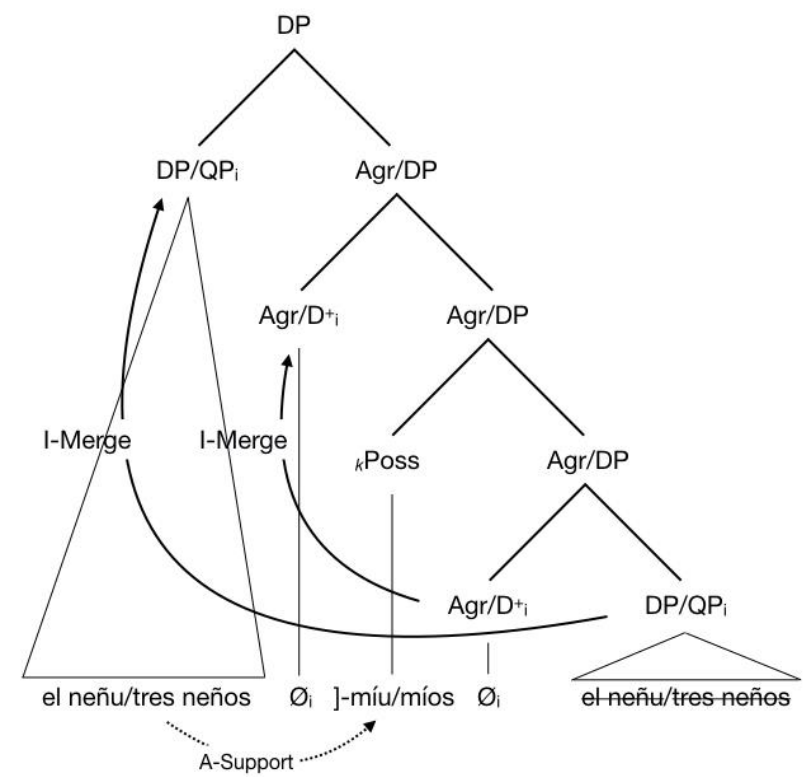

Figure 6. The postnominal possessive construction (Type III; e.g. el neñu míu)

As in Figure 3 (Type I), an agreement chain traverses this structure; but, unlike in Figure 3, what moves to the higher Spec, Agr/D is a whole nominal structure, which may comprise a D (les neñes mies; the-FM.PL girl-FM.PL myFM.PL), a Q (tres neñes mies; three girl-FM.PL my-FM.PL), or a D/Q sequence (les tres neñes míes; the-FM.PL three girl-FM.PL my-FM.PL) preceding the NP. This clearly takes apart this prenominal possessive construction (Type III) and the pronominal possessive one (Type I), as the latter cannot be anteceded by a Q (* tres mios neñes) or a $\mathrm{D} / \mathrm{Q}$ (* les tres mios neñes; but ${ }^{\checkmark}$ les mios tres neñes). This is a strong justification for the claim that the determiner is an obligatory dummy unit (cf. * mios neñes), independent from the internal QP/NP of the possessive base, in the pronominal possessive construction (Type I), whilst it is a component part of a moved DP in the prenominal possessive one (Type III). Note that Agr/D ${ }^{+}$, but not Agr/D, appears to raise with it its subcategorization requirements, as it asks for the completion of the Spec position by its former complement.

In the case of the prenominal possessive construction (Type I), I have suggested that the possessive agrees in number, but not in gender, because full $\varphi$ agreement (number + gender) is required to be PF-checked only once for a single agreement chain. As a consequence, $\mathrm{d}_{k}$ and QP/NP agree in gender and number (satisfying the PF-condition), whilst the possessive only exhibits LF-motivated number agreement, a requirement from which gender, as a classificatory feature, is excluded. The postnominal possessive construction (Type III) is however different, in that now there are only two independent candidates for agreement, 
namely, DP/QP (which, if present, comprises the article) and Poss. As a consequence, ${ }_{k}$ Poss is forced to agree in number and gender, as illustrated by the examples (13)-(16) above.

The remaining alternatives to the constructional types I and III are different, according to my analysis, in that they do not deploy Agr/D raising, albeit they are compatible with Bernstein's (2006: 65) 'XP-raising' kind of analysis for deriving the postnominal placement of the possessive. The solutions concerned entail E-merging a mixed adverbial/pronominal atom (P/D), along the lines of Kayne $(1982,1993)$, to the possessive base. This is shown in Figure 7.

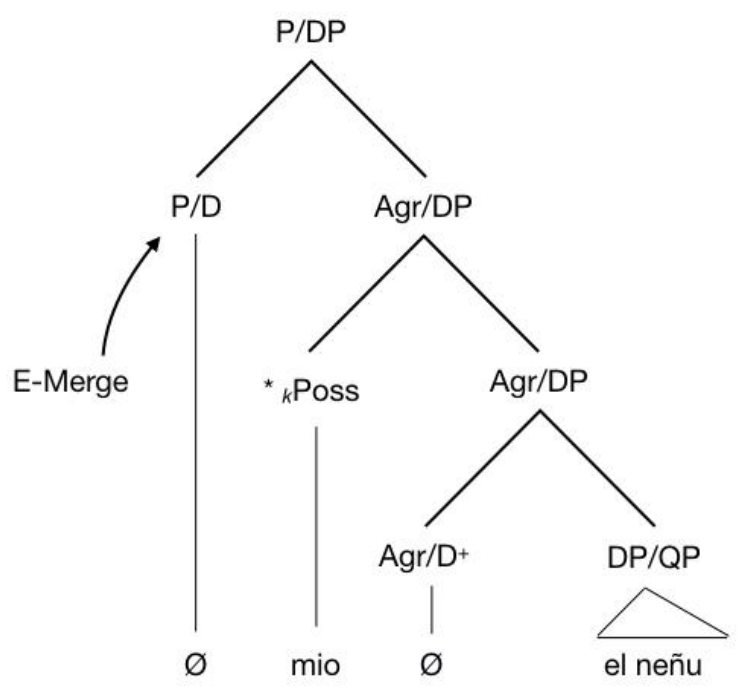

Figure 7. Postnominal possessive constructions (Type II: e.g. el neñu mio; and Type IV: e.g. el neñu de mio). Intermediate structure

Interestingly, this P/D atom has both a phonologically realized (Western and Central Asturian) and a phonologically null variant. Starting with the phonologically null variant, Figure 7 necessarily corresponds to an intermediary stage, as ${ }_{k}$ Poss still requires phonological support, which an abstract atom cannot provide. What happens next is that the DP/QP moves to Spec, P/DP and the condition is fulfilled. The resulting configuration is the one in Figure 8, corresponding to the postnominal possessive construction of Type II. In this configuration, ${ }_{k}$ Poss is not PF-committed to agree in $\varphi$-features (number + gender) once DP/QP has escaped from the Agr/DP umbrella. As before, it just shows number variation for LF reasons. 


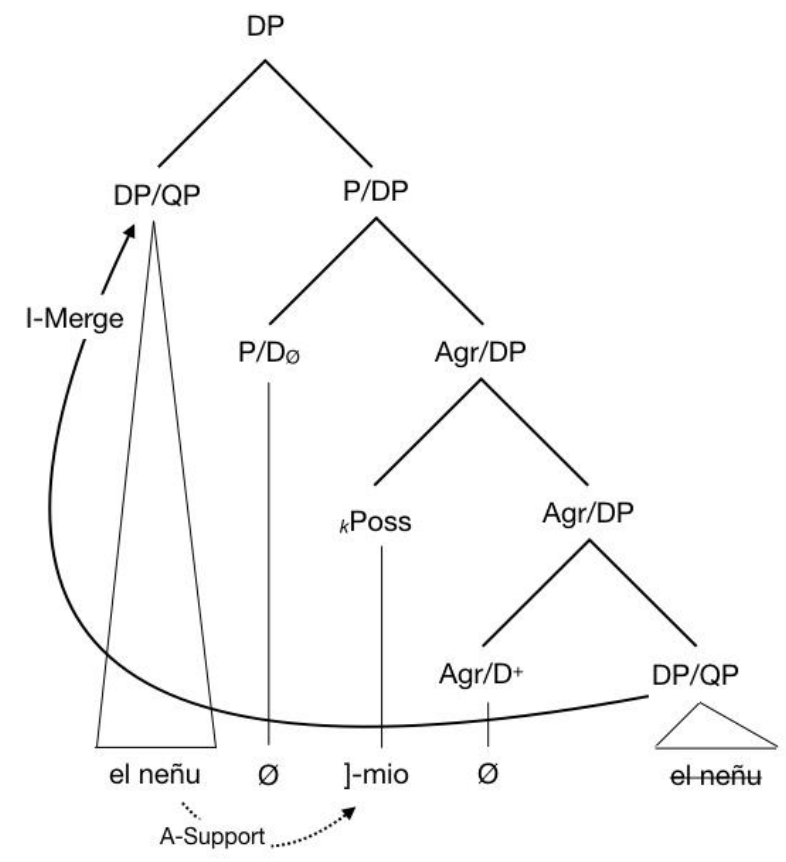

Figure 8. Postnominal possessive construction (Type II: e.g. el neñu mio)

Alternatively, P/D may be phonetically realized as $d e$ 'of' in Western and Central Asturian (de $\mathrm{P} / \mathrm{D})$. In this case, ${ }_{k}$ Poss receives support from this phonologically realized atom and Affix Support is fulfilled. Thus, no dummy determiner is required in this case, contrary to Type I (see Figure 3). However, de in turn requires the same kind of support, so something must happen next. Apparently, a DP/QP is banned form the Spec, ${ }_{d} \mathrm{P} / \mathrm{D}$ position (arguably, for case reasons), and the next available candidate to move is the lower Agr/DP (which purportedly does not impose a case condition). Note that when this happens, $\mathrm{DP} / \mathrm{QP}$ and ${ }_{k}$ Poss are not under the same structural agreement umbrella anymore, and therefore they are not formally committed to agree at all (neither in number nor gender features). Indeed, the prediction is borne out, as attested by the periphrastic possessive construction (Type IV). In this construction, the determiner at the front of the phrase is a component part of the most embedded DP/QP (not the dummy variant), which pied-pipes with Agr, and the possessive exhibits an invariable version of the neutral form (see Table 1). ${ }^{9}$ In the case of the 1 st and 2nd persons for more than one possessor, the masculine is chosen as a default invariable form. Figure 9 offers the complete skeleton of this construction. ${ }^{10}$

9 Among the several examples of this construction in Rodríguez Castellano (1957: 184), just one, corresponding to the meridional area of the Central variety, shows the plural form (unas navayas de sós, some knives of 3.PL; note that the feminine plural forms - as of this example are clearly taken from Spanish). Unfortunately, no accompanying comment about the representativeness of this example is made.

10 If Neira's (1979) observation is correct, this periphrastic form of the possessive construction is constrained by a 'definiteness effect' in the most meridional area of the Central variety, so it must obligatorily comprise a QP. Thus, one finds in this sub-variety contrasts like el mio preu (the my meadow) and un preu de mio 


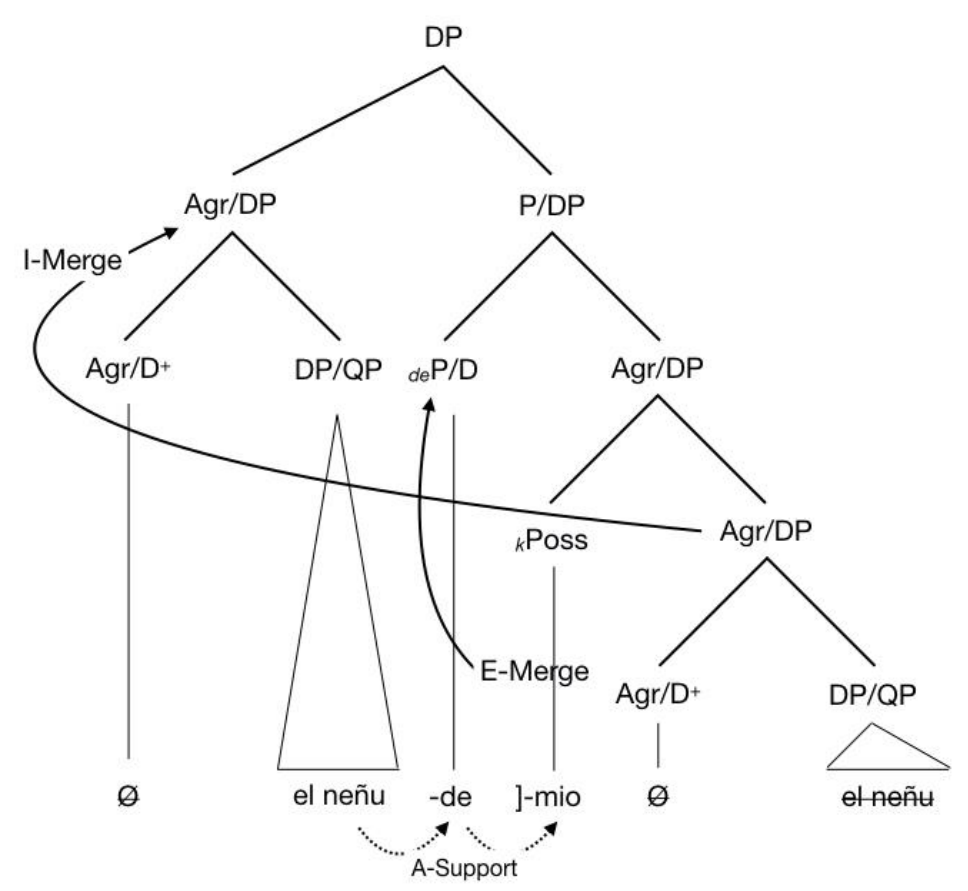

Figure 9. Periphrastic possessive construction (Type IV: e.g. el neñu de mio)

To conclude this section, Table 2 offers a specification of the different axes of micro-variation thus far identified, which have mostly to do with the subcategorization properties of the Agr/D atom of the possessive base (I vs. II, III, IV), the capabilities of Agr/D (I-Merge) and P/D (E-Merge) for merging to the possessive base (I, III vs. II, IV), and the phonological realization of $\mathrm{P} / \mathrm{D}$, with the corresponding associated properties for left-hand side recursion legitimation (II vs. IV).

Table 2. Main sources of micro-variation of the Asturian possessive construction types

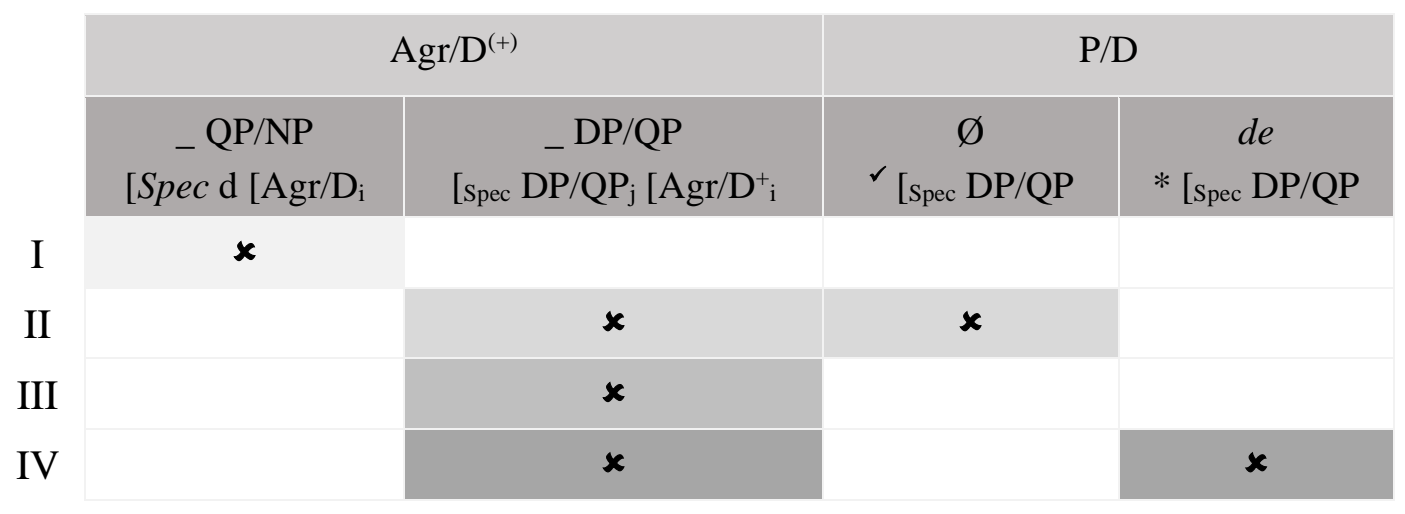

(a meadow of mine), but $*$ el preu de mio (the meadow of mine) is not attested (Neira 1976: 109). For an analysis of this effect, see Lorenzo (1998: 29-33). 


\section{Agreement asymmetries in Asturian possessive DPs}

Some details concerning the agreement facts typical of the different kinds of possessive DPs in Asturian can be related with the phenomenon referred to as 'lazy concord' in the literature (Haiman \& Benincà 1992, Ramson 2008). This term is used to refer to cases wherein a particular agreement relation is established differently depending of the relative order (in observational terms) between the relata. For example, verb-subject agreement in Standard Arabic affects number and gender in the SV order, but only gender in the alternative VS one (Aoun et al. 1994). At the DP level, demonstratives in Moroccan Arabic agree with the noun in number and gender when postnominal, but they exhibit a bare form when prenominal (Shlonsky 2004). Thus, for instance, the asymmetry in Asturian between the prenominal possessive construction (Type I) and the postnominal possessive one of Type III appears to be assimilable to this general pattern of 'lazy concord,' in that the possessive exhibits number and gender agreement in the latter (el пеп̃u ті́ the.MS.SG boy-MS.SG my-MS.SG, los neños míos the.MS.PL boy-MS.PL my-MS.PL, la neña mía the.FM.SG girl-FM.SG myFM.SG, les neñes mies the.FM.PL girl-MS.PL my-FM.PL), but only agrees in number in the former (el/la mio neñu/a the.MS/FM.SG my-SG boy/girlMS/FM.SG, los/les mios neños/es the.MS/FM.PL my-PL boy/girl-MS/FM.PL).

Ackema \& Neeleman $(2003,2004)$ have dealt with similar cases at the clausal level. Their analytical framework can be easily projected to the DP level (Bonet 2013) and potentially accommodated to the Type I/Type III contrast in Asturian as follows:

(a) Poss and QN/NP end up under the same projection (Agr/DP) in the case of Type I (see Figure 3) (23a), which is then processed as one single prosodic phrase (I) (Nespor \& Vogel 2007) at PF (23b), a circumstance that favors 'lazy agreement' or 'agreement weakening' (23c):
a. [Agr/DP Agr/Di $[$ Poss \#, $\left.\gamma] \ldots \mathrm{t}_{\mathrm{i}}[\mathrm{QP} / \mathrm{NP} \#, \gamma]\right]$
b. $\left\{I_{I}[\text { Poss \#, } \gamma][\mathrm{QP} / \mathrm{NP} \#, \gamma]\right\}_{I}$
c. $\left\{{ }_{I}[\text { Poss \#, } \gamma][\mathrm{QP} / \mathrm{NP} \#, \gamma]\right\}_{I} \rightarrow\left\{{ }_{I}[\mathrm{Poss} \#][\mathrm{QP} / \mathrm{NP} \#, \gamma]\right\}_{I}$

(23c) formalizes as a transformational (or context-sensitive) rule holding at the PF-interface setting that Poss is not inflected for gender if sharing its set of $\varphi$-features (number + gender) with a quantifier or nominal constituent within the same prosodic phrase.

(b) Contrarily, DP/QP ends up outside Agr/DP, whilst Poss remains there, in the case of Type III (see Figure 6) (24a). Thus, they are split into two different prosodic phrases $(I)$ at $\mathrm{PF}(24 \mathrm{~b})$, a situation not compatible with 'agreement weakening:'

$$
\begin{aligned}
& \text { a. }\left[\mathrm{DP}[\mathrm{DP} / \mathrm{QP} \#, \gamma]_{\mathrm{i}}\left[\mathrm{Agr} / \mathrm{DP} \text { Agr/Di }[\text { Poss \#, } \gamma] \mathrm{t}_{\mathrm{i}} \mathrm{t}_{\mathrm{j}}\right]\right] \\
& \text { b. }\left\{I_{I}[\mathrm{DP} / \mathrm{QP} \#, \gamma]\right\}_{I}\left\{{ }_{I}[\text { Poss \#, } \gamma]\right\}_{I}
\end{aligned}
$$

Ackema and Neeleman's formula thus appears to satisfactorily account for the Asturian contrast between these particular types. However, an overall consideration of the typology reviewed in the prior sections reveals that Ackema 
and Neeleman's basic condition neither captures a necessary nor a sufficient condition for the weakening facts in Asturian.

To begin with, the case of the periphrastic possessive construction (Type IV) illustrates that it is not explanatorily sufficient. Remember that in this case the possessive adopts a neutral form, which does not retain any agreement feature (el/la/los/les neñu/a/os/es de mío; the.MS.SG/the.FM.SG/the.MS.PL/the.FM.PL boy/girl/boys/girls of mine). Two extra facts require an explanation in this case, namely, (a) weakening applies to possessives which appear postnominal, and (b) it is a more radical form of weakening than in the case of Type III. Remember that according to my own explanation (see Figure 9), Type IV instantiates a case of 'agreement break:' DP/QP pied-pipes with Agr/DP, and, as a result, DP/QP and Poss split up and they lose their original agreement linkage. Moreover, the intermediary that remains between them is the P/D atom; thus, Poss is freed from showing any kind of particular agreement feature. This is illustrated in (25):

$$
\begin{aligned}
& \text { a. }\left[\mathrm{DP}[\mathrm{Agr} / \mathrm{DP} \mathrm{Agr} / \mathrm{D}[\mathrm{DP} / \mathrm{QP} \#, \gamma]]_{\mathrm{i}}\left[\mathrm{P} / \mathrm{DP} d_{e} \mathrm{P} / \mathrm{D}[\mathrm{Poss} \#, \gamma] \mathrm{t}_{\mathrm{i}}\right]\right] \\
& \text { b. }\left\{{ }_{I}[\mathrm{DP} / \mathrm{QP} \#, \gamma]_{I}\left\{{ }_{I} d e[\mathrm{Poss} \#, \gamma]\right\}_{I}\right. \\
& \text { c. }{ }^{?}\left\{{ }_{I}[\mathrm{DP} / \mathrm{QP} \#, \gamma]\right\}_{I}\left\{{ }_{I} d e[\text { Poss \#, } \gamma]\right\}_{I} \rightarrow\left\{{ }_{I}[\mathrm{DP} / \mathrm{QP} \#, \gamma]\right\}_{I}\left\{{ }_{I} d e[\mathrm{Poss}]\right\}_{I}
\end{aligned}
$$

Obviously, (25b) does not fit with Ackema and Neeleman's basic condition for weakening.

In this regard, the postnominal possessive construction of Type II is clarifying, as what one finds there is not that agreement is lacking, but an instance of postnominal 'weak' agreement. The syntactic structure corresponding to this Type II (see Figure 8), may be legitimately translated into a prosodic phrasing like (26b), which should not allow for weakening. However, against such an expectation, what one finds in this type of construction is a bona fide case of agreement weakening (el/la neñu/a mío, the.MS.SG/the.FM.SG boy/girl my.SG; los/les neños/es míos, the.MS.PL/the.FM.PL boys/girls my.PL) (26c):

$$
\begin{aligned}
& \text { a. } \left.\left[\mathrm{DP}[\mathrm{DP} / \mathrm{QP} \#, \gamma]_{\mathrm{i}}[\mathrm{P} / \mathrm{DP} \mathrm{P} / \mathrm{D} \text { [Poss \#, } \gamma] \text { Agr/D t } \mathrm{i}\right]\right] \\
& \text { b. }\left\{{ }_{I}[\mathrm{DP} / \mathrm{QP} \#, \gamma]\right\}_{I}\left\{{ }_{I}[\text { Poss \#, } \gamma]\right\}_{I} \\
& \text { c. }{ }^{?}{ }_{I}[\mathrm{DP} / \mathrm{QP} \#, \gamma]_{I}\left\{{ }_{I}[\text { Poss \#, } \gamma]\right\}_{I} \rightarrow\left\{{ }_{I}[\mathrm{DP} / \mathrm{QP} \#, \gamma]\right\}_{I}\left\{{ }_{I}[\text { Poss \#] }\}_{I}\right.
\end{aligned}
$$

Notice that in (26c), contrary to expectations, Poss ends up not being inflected for gender, albeit it belongs to a different prosodic phrase than the quantifier or nominal constituent.

According to my analysis in the previous section, the difference between Type III, with full agreement (Figure 8), and Type II, with agreement weakening (Figure 6), is that the former contains an agreement chain, which is lacking in the latter. Thus, my suggestion is that weakening is forbidden in Asturian when the constituents involved (DP/QP and Poss, in this case) are linked by an agreement chain, as in Type III; otherwise, the condition is relaxed and agreement weakens, as in Type II. Besides, in Type II, Poss is at the edge of an agreement head (Agr/D), whilst, in Type IV, agreement has been broken - Agr/DP raises and Poss becomes isolated from it. As a consequence, Poss still has to render (number) agreement at LF in Type II, whilst it unproblematically shows up in a radically impoverished form in Type IV. 
Asturian DPs exhibit an instance of another phenomenon which has been previously analyzed as involving a case of asymmetric concord, namely, 'count/mass' agreement (ALLA 2001: 323, Bonet 2013, Bonet et al. 2015, Burner 2016, Camblor \& Bowden 2005, Carretero García 2017, Mascaró 2011). In Asturian, ${ }^{11}$ 'mass' is expressed by a specific morphological exponent (-o), which is different from the masculine $(-u)$ and the feminine $(-a)$. Thus, pelu 'hair' (pilu, in the dialects with metaphony) refers to one specific piece of hair, whilst pelo refers to the hair as a certain kind of stuff; similarly, fierru 'iron' refers to a specific piece of iron, whilst fierro names the corresponding natural class. In the case of invariable nouns (cebolla 'onion,' carne 'meat,' etc.), the contrast is morphologically visible when accompanied by an adjective. Thus, cebolla cruda 'raw onion' refers to a piece of raw onion, and carne cruda 'raw meat' to a piece of raw meat; in contrast, cebolla crudo and carne crudo refer to uncooked onion and meat, respectively, in general (ALLA 2001: 322-327). The 'mass' morphology offers an instance of asymmetric agreement because adjectives do not display the mass morphology when prenominal; instead, the gender corresponding to the count modality spreads to the adjective in that position. The examples in (27) and (28) - from Bonet (2013: exs. 21 and 22) - illustrate this:
a. duru fierru ferruñosu
b. duru fierro ferruñoso hard iron rusty 'hard rusty iron'

a. guapa manzana madura

b. guapa manzana maduro good apple ripe 'good ripe apple'

\author{
MS, COUNT \\ MS, MASS
}

FM, COUNT

FM, MASS

Note that in the (b) examples the noun refers to the corresponding kinds of stuff. Notwithstanding this, the 'mass' morphology only spreads to the postnominal adjective, whilst the prenominal one adopts the gender corresponding to the countable-associated reading of the noun. Figure 10, which is based on Bonet (2013: ex. 23), offers a schematic view of how features spread in these cases of agreement asymmetry.
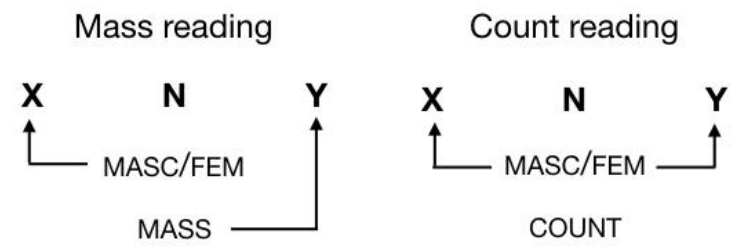

Figure 10. Asymmetric (left-hand side) and symmetric (right-hand side) feature spreading in Asturian DPs. Based on Bonet (2013: ex. 23)

11 This phenomenon is mostly restricted to the Central and Eastern dialects (Neira 1976: 95-102). 
Possessives also exhibit the morphological 'mass/count' distinction in Asturian. ${ }^{12}$ Thus, in connection with the asymmetry phenomenon, it is important to know how the mass feature spread to possessives in their different placements, and, crucially, how such spreading facts match with the asymmetries thus far reviewed.

First of all, ALLA (2001: 107) discusses that the mass morphology is incompatible with the prenominal possessive construction (Type I). It is important to remember that the gender morphology is also blocked in this position, which means that the phenomenon is not a mass-exclusive one. Only number stays active in prenominal possessives. Moreover, as I have already shown, 'lazy agreement' is not a prenominal-exclusive phenomenon in Asturian possessive DPs. In fact, mass morphology is also rejected in the periphrastic (postnominal) possessive construction (Type IV), together with gender and number morphology. Putting all these observations together, one can advance the hypothesis that agreement weakening obeys the same general conditions in the case of the mass morphology as in the case of the other morphologically variable features. Thus, mass morphology arguably does not show up in Type IV (Figure 9) because of the lack of any agreement linkage between Poss and DP/QP, after Agr/DP raising; as for the case of the prenominal Type I (Figure 3), Poss has only to render number at LF, a condition from which mass is exempted, arguably for its morphological connection with the classificatory gender distinction (Bonet \& Mascaró 2012: 91). Some relevant contrasts are offered in (29) - Type I - and (30) - Type IV:
a. el mio neñu
MS, COUNT
the.MS.SG my.SG boy.MS.SG
b. los mios neños
the.MS.PL my.PL boy.MS.PL
c. la mio neña
FM, COUNT
the.FM.SG my.SG girl.FM.SG
d. les mios neñes
the.FM.PL my.PL girl.FM.PL
e. el mio dineru the.MS.SG my.SG money.MS.MASS
f. la mio lleña the.FM.SG my.SG firewood.FM.MASS
MS, MASS
FM, MASS

(30)
a. el neñu de mio the.MS.SG boy-MS.SG of mine
MS, COUNT
b. los neños de mio
the.MS.PL boy-MS.PL of mine
c. la neña de mio
the.FM.SG girl-FM.SG of mine
d. les neñes de mio
the.FM.PL girl-FM.PL of mine
e. el dineru de mio
the.MS.SG money-MS.MASS of mine
FM, COUNT
MS, MASS

12 But restricted to the Central variety (Neira 1976: 108). 


\section{f. la lleña de mio $\quad$ FM, MASS \\ the.FM.SG firewood-FM.MASS of mine}

The gender/mass connection that these examples suggest may be captured by way of the following additions to Figure 4 above:
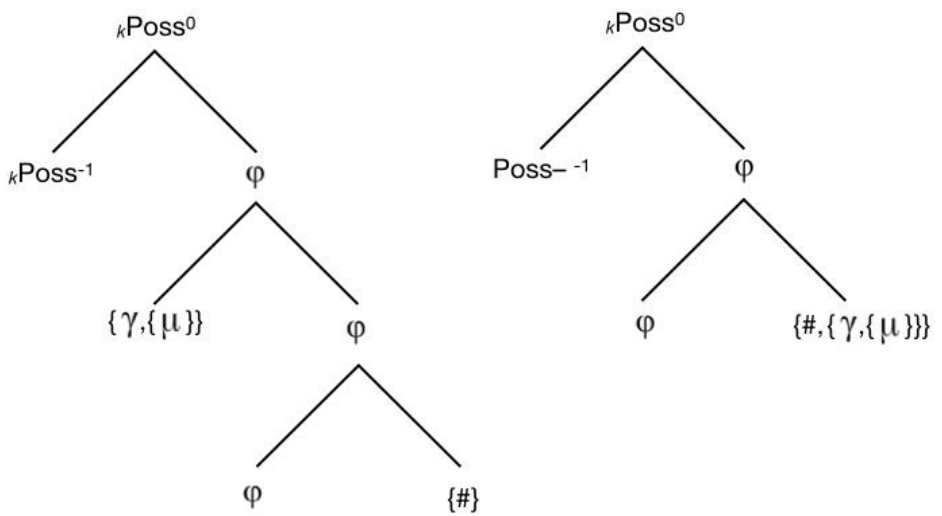

Figure 11. Complete sub-atomic composition of the Asturian possessives

In this figure, the mass morphology $(\mu)$ is deemed subordinated to the gender distinction $(\gamma)$ - which in turn is subordinated to the number distinction in the model corresponding to 1st and 2nd for more than one possessor (right-hand side). ${ }^{13}$ My suggestion is that the mass feature does not attain LF for checking, because its derivational fate is connected to the non-interpretable gender feature (Bonet \& Mascaró 2012: 91).

Contrarily to (29) and (30), the mass morphology is welcome in the postnominal possessive construction of Type III (Figure 6). Remember that in this construction Poss is fully inflected (number + gender). (31) illustrates it:

a. el neñu míu MS, COUNT the.MS.SG boy-MS.SG my-MS.SG

b. los neños míos the.MS.PL boy-MS.PL my-MS.PL

c. la neña mía the.FM.SG girl-FM.SG my-FM.SG

d. les neñes míes the.FM.PL girl-FM.PL my-FM.PL

e. el dineru mío the.MS.SG money-MS.MASS my-MASS

f. la lleña mío the.FM.SG firewood-FM.MASS my-MASS

FM, COUNT

MS, MASS

13 This figure is compatible with Mascaró's (2011: 12) and Bonet \& Mascaró's (2012: 92) point of view, according to which \# (in my figure) would correspond to the two-valued (SG/PL) COUNT feature. $\#_{\mathrm{PL}}$ is incompatible with $\gamma$, when the latter is specified positively for $\mu$. 
Finally, the postnominal possessive construction of Type II shows that weakening is a matter of configuration rather than of position alone. Poss is postnominal in this construction; however, both gender and mass morphology are excluded from occurring, and only number variation shows up. Remember that according to my analysis, the participation of a P/D head in this structure makes $\mathrm{DP} / \mathrm{QP}$ and Poss be unchained, albeit Poss is under the influence of a lower Agr/D (Figure 8) and thus has to render number checking at LF. Mass morphology, together with number and gender variation, do occur in the 1st and 2nd plurals of the most than one possessor form, which is also expected, given the dependency of the gender and mass features relative to the interpretable one in these particular cases. (32) illustrates the basic pattern for Type II:
a. el neñu mío
the.MS.SG boy-MS.SG my-SG
b. los neños míos
the.MS.PL boy-MS.PL my-PL
c. la neña mío
the.FM.SG girl-FM.SG my-SG
d. les neñes míos
the.FM.PL boy-FM.PL my-PL
dineru
mío
the.MS.SG money-MS.MASS my-SG
MS, MASS
FM, MASS
f. la lleña mío
MS, COUNT
FM, COUNT

The general conclusion appears to be that the manifestation of agreement weakening/asymmetry phenomena in association to the 'mass' morphology is governed exactly by the same general conditions that rule the morphological makeup of possessives in Asturian DPs.

\section{Concluding remarks}

In this paper I have suggested an integral view of the different kinds of possessive DPs in Asturian, which tries to derive their varying forms from an underlying predicative-like structure common to them. In this 'possessive base,' a possessive (Poss) and a nominal phrase (DP/QP/NP) are connected by means of an agreement head of a nominal type (Agr/D). The varying successive elaborations of such ultimate underpinning have been partially justified as due to the clitic $(k)$ condition of some of the constructive materials involved. In this sense, the proposal hopefully provides some relevant contributions to the Generalized Cliticization model of the Syntax-Phonology interaction (Richards 2016).

The ideas put forward in this paper may also contribute to the understanding of some nominal constructions of other Romance areas, which exhibit traits similar to the ones dealt with here as regards the Asturian language. For example, Picallo (1991: 132-133) observed that in Corsican, Toscan and the Catalan variants of Rosselló and Girona, the prenominal possessive shows up as default masculine/singular: 

a. la seu mare
the.FM.SG poss.3.MS.SG mother
'her/his/their mother'
b. e miò arrechie
the.FM.PL my.MS.SG earring-FM.PL
'my earrings'
c. i tu
calzoni
Catalan (Girona)
the.MS.PL your.MS.SG pant-MS.PL
d. els
meu
mainatges
the.MS.PL my.MS.SG child-MS.PL
'my children'
Corsican
Toscan
Catalan (Rosselló)

The present approach to possessive DPs that has been unfold in this paper may shed some light on these constructions, which may arguably entail the cooption of the abstract P/D element for fulfilling the role of $\mathrm{Agr} / \mathrm{D}$ in a structure like the one of Type I hypothesized here for Asturian (Figure 3). Somewhat complementarily, Calabrese and Napolitan have possessive periphrastic constructions similar to the Asturian Type (Figure 9), albeit one wherein the possessives agree with the QP/NP (Rohlfs 1949/1968: 129):
a. n'amico
d'u
mío
a-friend.MS.SG of-the.MS.SG mine.MS.SG
'a friend of mine'
b. na casa
d'e
sue
a house.FM.SG of-the.FEM.SG poss.3.FM.SG
'a house of her/his'

Calabrese
a. n'amich $\partial$
du
$\operatorname{mij} \partial$
a-friend.MS.SG of-the.MS.SG mine.MS.SG
'a friend of mine'
b. na conoscenza
da
mía
a acquaintance.FM.SG of-the.FEM.SG mine.FM.SG
'an acquaintance of mine'

These constructions are particularly interesting, as, on the one hand, the internal composition of the P/D item is phonologically transparent, and, on the other hand, it does not isolate the possessive in terms of agreement. Thus, its exact nature is arguably that of a P/AgrD (indeed, it exhibits agreement features overtly), a sort of mixed functional category somewhat expected by the frame that I have endorsed here.

Last, this contribution may hopefully illuminate other aspects of the syntax of Asturian, as, for example, the internal structure of adjectival complementation, considering the parallelisms observed between adjectives and possessives as regards the structural conditions for the 'counter/mass' variation. Such observations inspire the idea that similar skeletons and processes may be at work in both cases. All these phenomena are certainly worth of future detailed investigations. 


\section{References}

Academia de la Llingua Asturiana [ALLA]. 2001. Gramática de la llingua asturiana. Tercera Edición. Uviéu: Academia de la Llingua Asturiana.

Ackema, Peter \& Neeleman, Ad. 2003. "Context-sensitive spell-out". Natural Language and Linguistic Theory 21: 681-735. https://doi.org/10.1023/A:1025502221221

Ackema, Peter \& Neeleman, Ad. 2004. Beyond Morphology. Interface conditions on word formation. Oxford: Oxford University Press. https://doi.org/10.1093/acprof:oso/9780199267286.001.0001

Adger, David \& Ramchand, Gillian. 2005. Merge and move: Wh-dependencies revisited. Linguistic Inquiry 36: 161-193. https://doi.org/10.1162/0024389053710729

Aoun, Joseph, Bennamoun, Elabbas \& Sportiche, Dominique. 1994. "Agreement, word order, and conjunction in some varieties of Arabic". Linguistic Inquiry 25: 195-220.

Ausín, Adolfo \& Fernández-Rubiera, Francisco J. 2017. "Laísmo and "le-for-les": To agree or not to agree". In S. Perpiñán, D. Heap, I. Moreno-Villamar \& A. Soto-Corominas (eds.), Romance Langages and Linguistic Theory II. Selected Paper from the 44th Linguistic Symposium on Romance Languages (LSLR), London, Ontario, 101-106. Amsterdam \& Philadelphia: John Benjamins.

Bernstein, Judy. 2006. "On the morpho-syntax of possessive constructions". Recherches Linguistiques de Vincennes 34: 55-75. https://doi.org/10.4000/rlv.1364

Bernstein, Judy \& Tortora, Christina. 2005. "Two types of possessive forms in English". Lingua 115: 1221-1242. https://doi.org/10.1016/j.lingua.2004.03.002

Bonet, Eulàlia. 2013. "Agreement in two steps (at least)". In O. Matushansky \& A. Marantz, Distributed Morphology today: Morphemes for Morris Halle (eds.), 167-184. Cambridge: MIT Press. https://doi.org/10.7551/mitpress/9780262019675.003.0010

Bonet, Eulàlia, Lloret, Maria Rosa \& Mascaró, Joan. 2015. “The prenominal allomorphy syndrome," in E. Bonet, M.R. Lloret \& J. Mascaró (eds.), Understanding allomorphy. Perspectives from Optimality Theory, 5-44. London: Equinox. https://doi.org/ 10.1558/equinox.25215

Bonet, Eulàlia \& Mascaró, Joan. 2012. "Asimetrías de concordancia en el SD: el rasgo de masa en asturiano”. In A. Fábregas, E. Felíu, J. Martín \& J. Pazó (eds.), Los límites de la morfología. Estudios ofrecidos a Soledad Varela Ortega, 91-104. Madrid: UAM Ediciones.

Brody, Michael. 1997. "Perfect chains". In L. Haegeman (ed.), Elements of grammar. Kluwer International Handbook of Linguistics, 139-167. Dordrecht: Springer. https://doi.org/10.1007/978-94-011-5420-8_3 
Burner, Matthew. 2016. "El neutro de materia en asturiano: un acercamiento sintáctico al fenómeno en cuanto a la especificidad, genericidad y la posición del adjetivo". Revista de Filoloxía Asturiana 16, 49-62.

Camblor, Maite \& Wood Bowden, Herriet. 2005. "The mass neuter phenomenon in Asturian: adjectives and agreement". Revista de Filoloxía Asturiana 5, 19-40.

Cano, Ana, Conde Sáiz, María Victoria, García Arias, Xosé Lluis \& García González, Francisco. 1976. Gramática bable. Madrid: Ediciones Naranco.

Cardenaletti, Anna. 1998. "On the deficient/strong opposition in possessive systems. In A. Alexiadou \& C. Wilder (eds.), Possessors, predicates and movement in the Determiner Phrase, 17-53. Amsterdam: John Benjamins. https://doi.org/10.1075/la.22.03car

Carretero Garcia, Paloma. 2017. "Agreement in Asturian". In M. Butt \& T. Holloway King (eds.), Proceedings of the LFG'17 Conference (University of Konstanz), 188-208. Stanford, CA: CSLI.

Chomsky, Noam. 1995. The minimalist program. Cambridge, MA: MIT Press. https://doi.org/10.7551/mitpress/9780262527347.001.0001

Chomsky, Noam. 2013. "Problems of projection". Lingua 130: 33-49. https://doi.org/10.1016/j.lingua.2012.12.003

DeMello, George. 1992. "LLe' for 'les' in the spoken educated Spanish of eleven cities". Canadian Journal of Linguistics 37, 407-430. https://doi.org/10.1017/S0008413100022027

Farkas, Donka F. 1990. "Two cases of underspecification in morphology". Linguistic Inquiry 21, 539-550.

Haiman, John \& Benincà. 1992. The Raetho-Romance languages. London: Routledge.

Hornstein, Norbert, Nunes, Jairo \& Grohmann, Kleanthes K. 2005. Understanding minimalism. Cambridge: Cambridge University Press. https://doi.org/10.1017/CBO9780511840678

Kayne, Richard. 1982. "Predicates as arguments. Verbs and nouns". GLOW Newsletter 8: 24.

Kayne, Richard. 1993. "Toward a modular theory of auxiliary selection". Studia Linguistica 47: 3-31. https://doi.org/10.1111/j.1467-9582.1993.tb00837.x

Kayne, Richard. 1994. The antisymmetry of syntax. Cambridge, MA: The MIT Press.

Lorenzo, Guillermo. 1998. Possessive constructions in the dialects of Asturian. A micro-parametric approach. Catalan Working Papers in Linguistics 6: 2340.

Mascaró, Joan. 2011. "The realization of features in asymmetric agreement in DPs”. Snippetts 23: 11-12.

Nespor, Marina \& Vogel, Irene. 2012. Prosodic phonology. Whit a new foreword. Berlin: De Gruyter Mouton.

Neira, Jesús. 1976. El bable. Estructura e historia. Salinas, Asturias: Ayalga.

Picallo, Carmen. 1991. Funcions dobles: Tres estudis de Sintaxi Catalana. Ph.D. Universitat Autònoma de Barcelona. 
Ramson, Sabrina. 2008. Lazy concord in the Central Ladin feminine DP: A case study on the interaction between Morphosyntax and Semantics. Ph.D. Thesis, Università degli Studi di Padova.

Richards, Norvin. 2016. Contiguity theory. Cambridge, MA: The MIT Press. https://doi.org/10.7551/mitpress/10542.001.0001

Ritter, Elizabeth. 1993. “Where's gender”. Linguistic Inquiry 24, 795-803.

Rodríguez Castellano, Lorenzo. 1957. "El posesivo en el dialecto asturiano". Boletín del Instituto de Estudios Asturianos 11/31: 171-187.

Rohlfs, Gerhard. 1949/1968. Grammatica storica della lingua italiana e dei suoi dialetti. Morfologia. Torino: Einaudi.

Shlonsky, Ur. 2004. "The form of Semitic Noun Phrases". Lingua 114: 14651526. https://doi.org/10.1016/j.lingua.2003.09.019

Szabolsci, Anna. 1981 "The possessive construction in Hungarian: A configurational category in a non-configurational language". Acta Linguistica Academiae Scientiarum Hungaricae 31: 261-289.

Szabolsci, Anna. 1983. "The possessive that run away from home". The Linguistic Review 3: 89-102. https://doi.org/10.1515/tlir.1983.3.1.89

Zamora Vicente, Alonso. 1985. Dialectología española. Segunda edición muy aumentada. Madrid: Gredos. 